\title{
Fitomedicamentos utilizados na medicina popular e suas potencialidades pouco
}

\section{exploradas}

\author{
Phytomedicines used in popular medicine and their underexplored potential
}

Fitomedicinas utilizadas en la medicina popular y su potencial poco explorado

Recebido: 09/11/2021 | Revisado: 18/11/2021 | Aceito: 30/11/2021 | Publicado: 11/12/2021

\author{
Ana Graziela Soares Rêgo \\ ORCID: https://orcid.org/0000-0003-3003-954X \\ Centro Universitário UniFacid Wyden, Brasil \\ E-mail: grazielarego@hotmail.com \\ Liana Cynthia de Macedo Reis \\ ORCID: https://orcid.org/0000-0001-7304-7713 \\ Instituto Federal de Educação, Ciência e Tecnologia do Piaú, Brasil \\ E-mail: lianareis@ifpi.edu.br \\ Francisco Laurindo da Silva \\ ORCID: https://orcid.org/0000-0001-6837-4509 \\ Centro Universitário UniFacid Wyden, Brasil \\ E-mail: flspb@yahoo.com.br
}

\begin{abstract}
Resumo
O estudo teve como objetivo demonstrar que espécies vegetais de uso comum na medicina popular, liberados para uso pela ANVISA e descritas na literatura científica, são detentoras de grande potencial terapêutico e ainda não foram exploradas em todas as suas potencialidades. Foi realizado um levantamento na Farmacopeia Brasileira - ANVISA. A partir desse levantamento foram selecionadas, de forma aleatória, três espécies vegetais: Achyrocline satureioides, Echinodorus grandiflorus e Schinus terebinthifolius. Logo após, foi realizada uma prospecção tecnológica das mesmas, a fim de identificar possíveis patentes relacionadas às espécies vegetais. Após a busca nas bases de dados, foi encontrado um total de 28 patentes para a espécie A. satureioides, 22 patentes para a espécie E. grandiflorus e 38 patentes para a espécie S. terebinthifolius. Após a utilização dos critérios de inclusão e exclusão, restou um total de 8 patentes para a espécie $A$. satureioides, 8 patentes para a espécie E. grandiflorus e 8 patentes para a espécie $S$. terebinthifolius. Ainda é reduzido o número de depósitos de patentes envolvendo as espécies vegetais estudadas no setor de serviços e/ou produtos voltados para a saúde humana, visto que todas as espécies já são descritas na literatura científica, são de uso comum na medicina popular e fazem parte da Farmacopeia Brasileira. Além disso, nem todos os usos descritos pela medicina popular, através de estudos etnofarmacológicos, são abrangidos.
\end{abstract}

Palavras-chave: Biotecnologia; Plantas medicinais; Patentes.

\begin{abstract}
The study aimed to demonstrate that plant species commonly used in folk medicine, released for use by ANVISA and described in the scientific literature, have great therapeutic potential and have not yet been fully explored. A survey was carried out in the Brazilian Pharmacopoeia - ANVISA. From this survey, three plant species were randomly selected: Achyrocline satureioides, Echinodorus grandiflorus and Schinus terebinthifolius. Soon after, a technological survey of them was carried out in order to identify possible patents related to plant species. After searching the databases, a total of 28 patents for the species A. satureioides, 22 patents for the species E. grandiflorus and 38 patents for the species $S$. terebinthifolius were found. After using the inclusion and exclusion criteria, there remained a total of 8 patents for the species A. satureioides, 8 patents for the species E. grandiflorus and 8 patents for the species S. terebinthifolius. The number of patent filings involving plant species studied in the service sector and/or products aimed at human health is still reduced, since all species are already described in the scientific literature, are in common use in popular medicine and are part of of the Brazilian Pharmacopoeia. Furthermore, not all uses described by folk medicine through ethnopharmacological studies are covered.
\end{abstract}

Keywords: Biotechnology; Medicinal plants; Patents.

\section{Resumen}

El estudio tuvo como objetivo demostrar que las especies de plantas comúnmente utilizadas en la medicina popular, liberadas para su uso por ANVISA y descritas en la literatura científica, tienen un gran potencial terapéutico y aún no se han explorado por completo. Se realizó una encuesta en la Farmacopea Brasileña - ANVISA. De este estudio, se seleccionaron al azar tres especies de plantas: Achyrocline satureioides, Echinodorus grandiflorus y Schinus terebinthifolius. Poco después, se realizó un relevamiento tecnológico de los mismos con el fin de identificar posibles 
patentes relacionadas con especies vegetales. Después de buscar en las bases de datos, se encontraron un total de 28 patentes para la especie A. satureioides, 22 patentes para la especie E. grandiflorus y 38 patentes para la especie $S$. terebinthifolius. Después de utilizar los criterios de inclusión y exclusión, quedaron un total de 8 patentes para la especie A. satureioides, 8 patentes para la especie E. grandiflorus y 8 patentes para la especie S. terebinthifolius. El número de solicitudes de patente que involucran especies de plantas estudiadas en el sector de servicios y / o productos destinados a la salud humana aún es reducido, ya que todas las especies ya están descritas en la literatura científica, son de uso común en la medicina popular y forman parte de la Farmacopea. Además, no se cubren todos los usos descritos por la medicina popular a través de estudios etnofarmacológicos.

Palabras clave: Biotecnología; Plantas medicinales; Patentes.

\section{Introdução}

O Brasil é um país que contempla uma das maiores biodiversidades do planeta, abriga cerca de $20 \%$ das espécies animais, vegetais e de microrganismos. Estima-se que são mais de 100 mil espécies de animais, e cerca de 60 mil espécies de plantas catalogadas, além das espécies de fungos e liquens. Porém, apenas $8 \%$ foram estudadas para pesquisas de compostos bioativos e 1.100 espécies foram avaliadas em suas propriedades medicinais (Brasil, 2019; França, 2018).

Toda essa biodiversidade associada a uma rica diversidade étnica e cultural detém de um valioso conhecimento tradicional associado ao uso de plantas medicinais e possuem o potencial necessário para o desenvolvimento de pesquisas com resultados em tecnologias e terapêuticas apropriadas. Apesar das iniciativas do Ministério da Saúde dentro do Programa Nacional de Plantas Medicinais e Fitoterápicos (PNPMF), o potencial de uso sustentável da biodiversidade brasileira para produção de fitoterápicos ainda é pouco explorado comercialmente, apesar de as plantas medicinais e seus derivados serem há muito tempo utilizados pela população, nos cuidados primários com a saúde (Brasil, 2019; França, 2018; Oliveira, 2016).

Os medicamentos fitoterápicos podem ser descritos como sendo todos aqueles obtidos com emprego exclusivo de matérias-primas ativas vegetais. Como todos os medicamentos, os fitoterápicos de uso regulamentado são caracterizados pelo conhecimento da eficácia, dos riscos de seu uso, pela reprodutibilidade e constância de sua qualidade. O termo "fitomedicamento" não é utilizado oficialmente pela Agência Nacional de Vigilância Sanitária (ANVISA) e pelo PNPMF. Por definição, de acordo com o PNPMF o termo fitoterápico exclui "substâncias isoladas". Porém, neste estudo as potencialidades de inovação foram analisadas em um sistema que considera todos os produtos advindos da cadeia tecnológica e produtiva. Neste caso, o termo "fitomedicamento" utilizado no presente estudo, abrange os fitoterápicos incluindo as substâncias isoladas e os medicamentos desenvolvidos (Brasil, 2019).

Nesse contexto, o estudo teve como objetivo demonstrar que espécies vegetais de uso comum na medicina popular, liberados para uso pela ANVISA e descrito na literatura científica, são detentoras de grande potencial terapêutico e ainda não foram exploradas em todas as suas potencialidades.

\section{Metodologia}

O estudo trata-se de um estudo epidemiológico do tipo ecológico onde as medidas usadas representam características de grupos populacionais. Foi realizado um levantamento na Farmacopeia Brasileira - ANVISA. A Farmacopeia Brasileira é um compêndio farmacêutico nacional que estabelece, via textos farmacopeicos (capítulos, métodos e monografias), as exigências mínimas de qualidade, autenticidade e pureza de insumos farmacêuticos de medicamentos e de outros produtos sujeitos à vigilância sanitária. $\mathrm{O}$ não atendimento integral às exigências farmacopeicas poderá resultar no enquadramento do produto como alterado, adulterado ou impróprio para uso. Assim sendo, cabe à Farmacopeia Brasileira o estabelecimento dos parâmetros de aceitabilidade dos produtos disponibilizados à população brasileira, servindo de alicerce essencial para a consecução das ações de controle e fiscalização sanitária. Sendo assim, todos os fitoterápicos selecionados para o presente estudo estão descritos na Farmacopeia Brasileira $6^{\circ}$ Ed. - ANVISA (2019). 
A partir do levantamento na Farmacopeia Brasileira foram selecionadas, de forma aleatória, três espécies vegetais: Achyrocline satureioides (A. satureiodes), Echinodorus grandiflorus (E. grandiflorus) e Schinus terebinthifolius (S. terebinthifolius). Logo após, foi realizada uma prospecção tecnológica das mesmas, a fim de identificar possíveis patentes relacionadas às espécies vegetais.

A busca de patentes foi realizada em três bases de dados tecnológicas: Escritório Europeu de Patentes, EPO (Espacenet); Instituto Nacional da Propriedade Industrial (INPI) (Brasil) e LATIPAT (América Latina e Espanha), utilizando como descritores o nome científico das espécies e os nomes populares. Incluindo neste estudo as patentes que mencionassem essas palavras-chave no título e/ou resumo, considerando todos os pedidos de patente depositados.

As pesquisas foram realizadas durante os meses de setembro e outubro de 2020. Posteriormente, foram definidos os critérios de inclusão, como patentes explorando o nome das espécies científico e popular (Achyrocline satureioides/ Macela, Echinodorus grandiflorus / Chapéu-de-couro e Schinus terebinthifolius / Pimenta-rosa / Aroeira vermelha) e sua utilização no setor da saúde e os critérios de exclusão: patentes duplicadas/cruzadas nas bases de dados; títulos e trabalhos não voltados para a saúde humana.

\section{Resultados}

Após a busca nas bases de dados, foram encontrados um total de 28 patentes para a espécie A. satureioides, 22 patentes para a espécie E. grandiflorus e 38 patentes para a espécie S. terebinthifolius. Os totais de patentes encontrados em cada base de dados tecnológicos estão descritas na Tabela 1.

Tabela 1 - Descritores utilizados na busca e quantidade de patentes encontradas em cada base de dados.

\begin{tabular}{l|c|c|c|c}
\hline \multirow{2}{*}{$\begin{array}{c}\text { ESPECIE VEGETAL / } \\
\text { DESCRITORES } \\
\text { UTILIZADOS NA } \\
\text { BUSCA }\end{array}$} & \multicolumn{3}{|c|}{ BASES DE DADOS TECNOLOGICOS } & \multirow{2}{*}{$\begin{array}{c}\text { TOTAL DE } \\
\text { PATENTES }\end{array}$} \\
\cline { 2 - 5 } & EPO & INPI & LATIPAT & \\
\hline $\begin{array}{l}\text { Achyrocline satureioides/ } \\
\text { Macela }\end{array}$ & 6 & 10 & 12 & 28 \\
\hline $\begin{array}{l}\text { Echinodorus grandiflorus } \\
\text { Chapéu-de-couro }\end{array}$ & 2 & 10 & 10 & 38 \\
\hline $\begin{array}{l}\text { Schinus terebinthifolius / } \\
\text { Pimenta-rosa / Aroeira } \\
\text { vermelha }\end{array}$ & 4 & 17 & 17 & \\
\hline
\end{tabular}

Fonte: Dados da pesquisa (2020).

Após a utilização dos critérios de inclusão e exclusão, restou um total de 8 patentes para a espécie A. satureioides, 8 patentes para a espécie E. grandiflorus e 8 patentes para a espécie $S$. terebinthifolius. Todas as patentes estão descritas respectivamente na Tabela 2. 
Tabela 2 - Patentes de cada espécie vegetal após utilização dos critérios de exclusão.

\begin{tabular}{|c|c|c|c|}
\hline $\begin{array}{c}\text { ESPÉCIE } \\
\text { VEGETAL }\end{array}$ & PATENTES & DESCRIÇÃOO & ANO \\
\hline \multirow{8}{*}{ 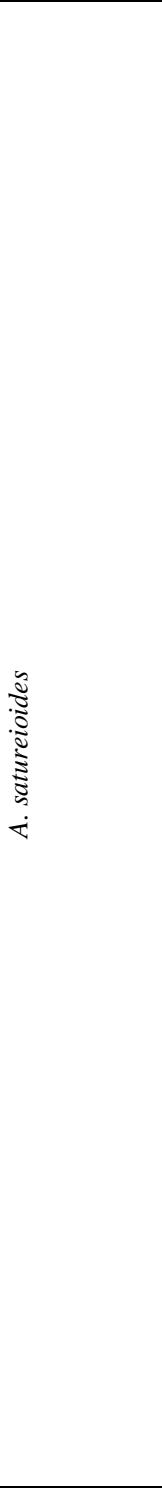 } & $\begin{array}{l}\text { PREPARAÇÃO DE PELE PARA USO } \\
\text { EXTERNO }\end{array}$ & $\begin{array}{l}\text { Preparação cutânea de uso externo com ação antioxidante eficaz para a } \\
\text { prevenção da oxidação dos componentes lipídicos da pele e para o } \\
\text { distúrbio oxidativo. }\end{array}$ & 1997 \\
\hline & $\begin{array}{c}\text { COMPLEMENTO ALIMENTAR PARA } \\
\text { AUXILIAR NO TRATAMENTO E CONTROLE } \\
\text { DE PROBLEMAS NO SISTEMA } \\
\text { RESPIRATÓRIO }\end{array}$ & $\begin{array}{l}\text { A presente fórmula vem pra exercer a função de coadjuvante no } \\
\text { tratamento de problemas no sistema respiratório, sendo constituída } \\
\text { pelos seguintes elementos: } 30 \text { a } 40 \% \text { de "A. satureoides" conhecida } \\
\text { popularmente como Macela e de } 60 \text { a } 70 \% \text { de azeite de oliva puro. }\end{array}$ & 2006 \\
\hline & $\begin{array}{c}\text { EXTRATO ALCOÓLICO DE TROPAEOLUM } \\
\text { MAJUS L. E A. SATUREIOIDES PARA O } \\
\text { TRATAMENTO DA ALOPECIA } \\
\text { ANDROGENÉTICA }\end{array}$ & $\begin{array}{l}\text { A consideração dos princípios ativos da planta Tropaeolum majus } L \text {. e } \\
\text { suas ações farmacológicas amplamente investigadas em suas folhas e } \\
\text { pecíolos para esse fim. O produto foi complementado com a flor de } A \text {. } \\
\text { satureoides. }\end{array}$ & 2010 \\
\hline & $\begin{array}{l}\text { COMPOSIÇÃO FARMACÊUTICA ANTIVIRAL } \\
\text { PARA LIBERAÇÃO CONTROLADA E SEU } \\
\text { PROCESSO DE PREPARAÇÃO }\end{array}$ & $\begin{array}{l}\text { A composição compreende extrato vegetal como ingrediente ativo, } \\
\text { preferivelmente extrato padronizado de A. satureioides, o qual possui } \\
\text { ação antiviral (HSV-1 e HSV-2). A composição para liberação } \\
\text { controlada compreende pelo menos um ingrediente ativo e um sistema } \\
\text { de polímeros, os quais retardam a liberação do ingrediente ativo na } \\
\text { cavidade oral, bem como provêem propriedades mucoadesivas, além de } \\
\text { incluir, opcionalmente, outros excipientes farmaceuticamente } \\
\text { aceitáveis. }\end{array}$ & 2010 \\
\hline & $\begin{array}{l}\text { PROCESSO PARA OBTER UM EXTRATO } \\
\text { PADRONIZADO DE QUERCETINA UM 3-0- } \\
\text { METILQUERCETINA DE FLORES E MACELA } \\
\text { (A. SATUREIOIDES), E COMPOSIÇÕES } \\
\text { COSMÉTICAS E FARMACEUTICAS } \\
\text { COMPREENDENDO O REFERIDO EXTRATO }\end{array}$ & $\begin{array}{l}\text { A presente invenção refere-se a um processo de extração para obter um } \\
\text { extrato padronizado de quercetina e 3-o-metilquecetina de } \\
\text { inflorescências da A. satureioides. Da mesma forma descreve } \\
\text { composições cosméticas, farmacêuticas e veterinárias contendo o } \\
\text { extrato mencionado acima, destinado para a prevenção e tratamento dos } \\
\text { danos que surgem de reações inflamatórias, microbianas e } \\
\text { oxidação/lipoperoxidação. O uso e método de aplicação do extrato de } \\
\text { macela são da mesma forma descritos. }\end{array}$ & 2012 \\
\hline & $\begin{array}{c}\text { AGENTE ATIVO DE ILUMINAÇÃO } \\
\text { CONTENDO EXTRATOS DE PLANTA, SEUS } \\
\text { USOS E COMPOSIÇÕES CONTENDO OS } \\
\text { MESMOS }\end{array}$ & $\begin{array}{l}\text { A presente invenção divulga uma composição cosmética destinada ao } \\
\text { clareamento da pele, mais particularmente um agente de clareamento } \\
\text { compreendendo o extrato de Alpinia officinarum ou a associação entre } \\
\text { extratos de Physalis angulata, Bidens pilosa e A. satureioides incluídos } \\
\text { em uma rede lipídica estruturada para distribuição de compostos } \\
\text { bioativos. }\end{array}$ & 2014 \\
\hline & $\begin{array}{c}\text { PREPARAÇÃO LIPOSSÔMICA } \\
\text { DE } A \text {. SATUREIOIDES (MACELA), } \\
\text { FLAVONOIDES E DERIVADOS } \\
\text { SEMISINTÉTICOS, PARA A PROTEÇÃO DO } \\
\text { TECIDO CEREBRAL CONTRA DANOS } \\
\text { ISQUÊMICO-VASCULARES E } \\
\text { NEURODEGENERATIVOS } \\
\end{array}$ & $\begin{array}{l}\text { A presente invenção refere-se ao tratamento de lesões cerebrais } \\
\text { isquêmico-vasculares e/ou neurodegenerativas pela administração de } \\
\text { um ou mais compostos da fórmula geral I em preparação } \\
\text { lipossomal. Estes compostos administrados na forma lipossomal têm } \\
\text { ação neuroprotetora, preventiva da morte neuronal pelo } \\
\text { envelhecimento, com ação protetora em doenças degenerativas como } \\
\text { Alzheimer e Parkinson. }\end{array}$ & 2014 \\
\hline & $\begin{array}{l}\text { FILME CICATRIZANTE, ANESTÉSICO E } \\
\text { ANTI-INFLAMATÓRIO; COMPOSIÇÃO E } \\
\text { SEUS USOS }\end{array}$ & $\begin{array}{l}\text { A presente invenção descreve um filme cicatrizante, anestésico e anti- } \\
\text { inflamatório compreendendo polímero natural e plantas medicinais } \\
\text { nativas da flora brasileira, mais precisamente, Spilanthes acmella e A. } \\
\text { satureoides. O filme aqui proposto é capaz de cicatrizar e contrair } \\
\text { eficazmente a ferida, além de anestesiar a área em que o mesmo é } \\
\text { aplicado. }\end{array}$ & 2016 \\
\hline \multirow{6}{*}{ 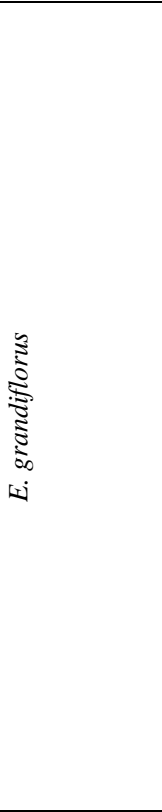 } & $\begin{array}{l}\text { PREPARAÇÃO PARA USO EXTERNO PARA } \\
\text { PELE }\end{array}$ & $\begin{array}{l}\text { Preparo para uso externo para a pele, eficaz na prevenção e redução da } \\
\text { caspa e queda de cabelos, além de promover a produção de cabelos e } \\
\text { ter excelentes ações inibidoras das atividades da tirosinase. }\end{array}$ & 1998 \\
\hline & $\begin{array}{c}\text { COMPOSIÇÃO COSMÉTICA NATURAL PARA } \\
\text { CREME, SHAMPOO ANTI-QUEDA, } \\
\text { SHAMPOO PARA MATAR PIOLHOS E } \\
\text { CONDICIONADOR }\end{array}$ & $\begin{array}{l}\text { A presente invenção, refere-se à composição cosmética natural para } \\
\text { fabricação de creme, shampoo anti-queda, shampoo para matar piolhos } \\
\text { e condicionador, as composições contêm elementos especiais que } \\
\text { usados conforme indicação, produzem resultados positivos para os } \\
\text { cabelos com maior rapidez e economia. }\end{array}$ & 2001 \\
\hline & $\begin{array}{c}\text { COMPLEMENTO ALIMENTAR PARA } \\
\text { AUXILIAR NO TRATAMENTO E CONTROLE } \\
\text { DE VITILIGO }\end{array}$ & $\begin{array}{l}\text { A presente formula vem para exercer a função de coadjuvante no } \\
\text { tratamento e controle de Vitiligo. }\end{array}$ & 2005 \\
\hline & $\begin{array}{l}\text { EXTRATO HIDROALCOÓLICO 75\% DAS } \\
\text { FOLHAS DE ECHINODORUS } \\
\text { MACROPHYLLUS, COM ATIVIDADE } \\
\text { ANTIINFLAMATÓRIA E ANALGÉSICA }\end{array}$ & $\begin{array}{l}\text { A invenção trata de um extrato hidroalcóolico } 75 \% \text { (EIIEm) obtido a } \\
\text { partir das folhas de Echinodorus macrophyllus (chapéu-de-couro), com } \\
\text { ação antiinflamatória aguda sistêmica e tópica, analgésica periférica e } \\
\text { central e aparente ausência de toxicidade aguda e sub-crônica orais, em } \\
\text { modelos experimentais animais. }\end{array}$ & 2008 \\
\hline & $\begin{array}{l}\text { AÇÃO INIBITÓRIA DE EXTRATOS DE } \\
\text { PLANTAS SOBRE LIPASE PANCREÁTICA }\end{array}$ & $\begin{array}{l}\text { O presente invento consiste na inibição enzimática da lipase } \\
\text { pancreática por extratos metanólicos de quatro plantas naturais do } \\
\text { Brasil, sendo chapéu-de-couro (E. grandiflorus) cana do brejo (Costus } \\
\text { spicatus), capim limão (Cymbopogon citratus) e carqueja (Baccharis } \\
\text { trimera). }\end{array}$ & 2012 \\
\hline & $\begin{array}{l}\text { COMPOSIÇÃO FARMACÊUTICA CONTENDO } \\
\text { ÁCIDOS ACONÍTICOS DE FOLHAS DE } \\
\text { ECHINODORUS GRANDIFLORUS E USO NO } \\
\text { TRATAMENTO DE ARTRITE }\end{array}$ & $\begin{array}{l}\text { A presente invenção descreve uma composição farmacêutica contendo } \\
\text { os ácidos cis e/ou trans-aconítico (ácido prop-1 -ene-1 ,2,3- } \\
\text { tricarboxílico), obtidos a partir de folhas de E. grandiflorus, para o } \\
\text { tratamento de artritereumatóide e osteoartrite. }\end{array}$ & 2014 \\
\hline
\end{tabular}




\begin{tabular}{|c|c|c|c|}
\hline & $\begin{array}{l}\text { COMPOSIÇÃO FARMACÊUTICA CONTENDO } \\
\text { UMA FRAÇÃO RICA EM FLAVONÓIDES DE } \\
\text { FOLHAS DE ECHINODORUS GRANDIFLORUS } \\
\text { E USO NO TRATAMENTO DE ARTRITE }\end{array}$ & $\begin{array}{l}\text { A presente invenção descreve uma composição farmacêutica contendo } \\
\text { uma fração pradronizada rica em flavonóides, a qual é composta por } \\
5,5 \text { a } 16,5 \% \text { massa/massa }(\mathrm{m} / \mathrm{m}) \text { de isoorientina, } 1,5 \text { a } 4,5 \% \mathrm{~m} / \mathrm{m} \text { de } \\
\text { isovitexina, } 3,5 \text { a } 10,5 \% \mathrm{~m} / \mathrm{m} \text { de swertijaponina (expresso em } \\
\text { isoorientina) e } 1 \text { a } 3 \% \mathrm{~m} / \mathrm{m} \text { de swertisina (expresso em isovitexina), } \\
\text { obtida a partir de folhas E. grandiflorus, e excipientes } \\
\text { farmaceuticamente aceitáveis para o tratamento de artrite reumatóide e } \\
\text { osteoartrite. }\end{array}$ & 2018 \\
\hline & $\begin{array}{c}\text { FORMULAÇÃO FARMACÊUTICA ORAL } \\
\text { OBTIDA ATRAVÉS DA TÉCNICA DE } \\
\text { INFUSÃO DO EXTRATO DE ECHINODORUS } \\
\text { GRANDIFLORUS }\end{array}$ & $\begin{array}{l}\text { A presente invenção descreve uma composição farmacêutica oral } \\
\text { compreendendo Extrato de } E \text {. grandiflorus (chapéu-de-couro), em um } \\
\text { veículo líquido, bem como a um processo para seu preparo. }\end{array}$ & 2019 \\
\hline \multirow{8}{*}{ 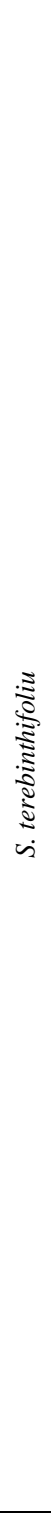 } & $\begin{array}{c}\text { COMPOSIÇÕES FARMACÊUTICAS PARA O } \\
\text { TRATAMENTO DE INFECÇÕES HPV } \\
\text { UTILIZANDO EXTRATOS DE SCHINUS } \\
\text { TEREBINTHIFOLIUS }\end{array}$ & $\begin{array}{l}\text { Preparo de formulações farmacêuticas adequadas para uso } \\
\text { medicamentoso, em particular para uso genital nas apresentações em } \\
\text { forma de sabões, tinturas, emulsões (pomadas, cremes e géis), } \\
\text { aerossóis, pastas, óvulos, supositório e similares, utilizadas para a } \\
\text { profilaxia e tratamento (como adjuvante) das infecções e câncer } \\
\text { cervical relacionados ao papilomavírus humano (HPV - human } \\
\text { papilloma virus) e as suas manifestações. }\end{array}$ & 2002 \\
\hline & CICATRIZANTE BIOFÁRMACO & $\begin{array}{l}\text { Medicamento fitoterápico com ação cicatrizante e antibacteriano em } \\
\text { feridas de pacientes diabéticos ou não, em micoses, unheiros, assaduras } \\
\text { e queimaduras. É um produto a base de plantas brasileiras contendo } \\
\text { extrato de quatro plantas (S. terebinthifolius, Physalis angulata, Cereus } \\
\text { hildemanianus, e Anadenanthera colubrina). }\end{array}$ & 2006 \\
\hline & $\begin{array}{l}\text { FITOMEDICAMENTO OBTIDO A PARTIR DE } \\
\text { SCHINUS TEREBINTHIFOLIUS }\end{array}$ & $\begin{array}{l}\text { A invenção se refere ao uso de substâncias isoladas de extratos } \\
\text { alcoólicos da } S \text {. terebenthifolius como medicamento fitoterápico com } \\
\text { atividades terapêuticas. }\end{array}$ & 2007 \\
\hline & $\begin{array}{c}\text { FORMULAÇÃO DE UMA COMPOSIÇÃO } \\
\text { FARMACÊUTICA A BASE DO EXTRATO } \\
\text { BRUTO E FRAÇÃO DO SCHINUS } \\
\text { TEREBINTHIFOLIUS (AROEIRA) COM } \\
\text { FINALIDADE TERAPÊUTICA NA } \\
\text { INFLAMAÇÃO E CICATRIZAÇÃO DE } \\
\text { AFECÇÕES DO ESTÔMAGO } \\
\end{array}$ & $\begin{array}{l}\text { A presente invenção refere-se ao processo de obtenção de formulação } \\
\text { de composição farmacêutica e seu uso na inflamaçâo e cicatrização do } \\
\text { estômago. }\end{array}$ & 2011 \\
\hline & $\begin{array}{l}\text { COMPOSIÇÃO A BASE DE EXTRATOS } \\
\text { VEGETAIS E NANOPARTÍCULAS DE } \\
\text { SÍLICAS DE ALTA ABSORÇÃO }\end{array}$ & $\begin{array}{l}\text { O presente invento descreve uma composição e sua formulação } \\
\text { hidradante contendo nanopartículasmesoporosas de silica como } \\
\text { facilitadoras e carreadoras de substâncias ativas dos extratos vegetais } \\
\text { oleosos e aquosos de Skyphnodendron barbatiman e S. terebinthifolius, } \\
\text { empregada principalmente no tratamento de infecções cutâneas } \\
\text { oportunistas. }\end{array}$ & 2012 \\
\hline & $\begin{array}{l}\text { COMPOSIÇÃO NEUROPROTETORA COMPRE } \\
\text { ENDENDO EXTRATO } \\
\text { OU FRAÇÕES DE SCHINUS TEREBINTHIFOLI } \\
\text { US COMO INGREDIENTE ATIVO }\end{array}$ & $\begin{array}{l}\text { A presente invenção tem efeitos de proteção das células nervosas } \\
\text { cranianas e uma baixa citotoxicidade de acordo com a atividade } \\
\text { inibitória contra a toxicidade do glutamato em uma linha celular N18- } \\
\text { RE-105 com as propriedades das células cerebrais, de modo que } \\
\text { o } S \text {. terebinthifolius extrato ou uma fração do mesmo pode ser usado na } \\
\text { prática para uma composição farmacêutica para proteção de nervos, } \\
\text { uma composição farmacêtica para prevenção e tratamento de doenças } \\
\text { cerebrais ou alimento saudável para a referida finalidade. }\end{array}$ & 2012 \\
\hline & $\begin{array}{c}\text { COMPOSIÇÃO COMPREENDENDO } \\
\text { EXTRATO DE GUAÇATONGA E EXTRATO } \\
\text { DE AROEIRA E USO DOS MESMOS }\end{array}$ & $\begin{array}{l}\text { A presente invenção refere-se a uma composição cosmética } \\
\text { compreendendo extrato de Guaçatonga (Casearia silvestres), extrato de } \\
\text { Aroeira ( } S \text {. terebinthifolius) e adjuvantes cosmeticamente aceitáveis } \\
\text { direcionada à prevenção e/ou tratamento de sinais ocasionados pelo } \\
\text { envelhecimento da pele. }\end{array}$ & 2014 \\
\hline & $\begin{array}{c}\text { DESENVOLVIMENTO DE UM } \\
\text { FITOTERÁPICO COM AÇÃO CICATRIZANTE } \\
\text { PREPARADO A PARTIR DO EXTRATO } \\
\text { HIDROALCOÓLICO DE SCHINUS } \\
\text { TEREBINTHIFOLIUS, BIOVEICULADO COM } \\
\text { QUITOSANA } \\
\end{array}$ & $\begin{array}{l}\text { A presente invenção refere-se ao processo de produção de uma } \\
\text { formulação farmacêutica em gel, denominada FExStrQ, contendo } \\
\text { extrato hidroalcoólico de } S \text {. terebinthifolius e utilizando como meio } \\
\text { dispersante o polímero de quitosana. }\end{array}$ & 2017 \\
\hline
\end{tabular}

Fonte: Dados da pesquisa (2020).

\section{Discussão}

O Brasil é detentor de uma rica diversidade cultural e étnica que resultou em um acúmulo considerável de conhecimentos e tecnologias tradicionais, passados de geração a geração, entre os quais se destacam o vasto acervo de conhecimentos sobre manejo e o uso de plantas medicinais. Neste sentido, entende-se que o Brasil, com seu amplo patrimônio genético e sua diversidade cultural, tem a oportunidade de estabelecer um novo modelo de desenvolvimento próprio e soberano na área de saúde e no uso de plantas medicinais e fitomedicamentos, modelo esse que preze pelo uso sustentável dos recursos 
da biodiversidade e respeite os princípios éticos. Além disso, o Brasil possui grande parte de sua biodiversidade inexplorada e apresenta enorme potencial na produção de insumos e processos que podem ser patenteados na área de produtos naturais. Embora políticas recentes tenham estimulado a proteção e a comercialização de resultados de pesquisas nacionais, é necessário que as universidades e empresas brasileiras atentem para a importância das patentes como ferramenta competitiva em um mercado globalizado (Brasil, 2019; Gutiérrez, 2012).

A espécie vegetal A. satureioides, popularmente conhecida como "macela", é uma das 25 Achyrocline spp. descritas em território brasileiro. É uma erva aromática de tamanho médio, comumente encontrado na América tropical e subtropical. $\mathrm{Na}$ medicina popular é utilizada em infusões com ação ansiolítica, digestiva, carminativa, antiespasmódica, colagogo, eupéptica e emenagogo. Estudos anteriores in vitro e in vivo confirmaram o uso tradicional de A. satureioides como antiinflamatório, hepatoprotetor, antioxidante, imunomodulador, antimicrobiano, antitumoral e fotoprotetor. Também é bastante utilizada na fabricação de cremes cosméticos por seu alto teor de flavonoides e antioxidantes. Investigações sobre a sua composição química encontraram os flavonoides quercetina, 3-O-metilquercetina e luteolina como os principais compostos em extratos de inflorescências de A. satureioides. No entanto, seu principal uso comercial é como aromatizante na indústria de bebidas; especialmente, como parte da composição de inúmeras bebidas à base de plantas, com ou sem álcool. De acordo com a tabela 2 observa-se que existe uma variedade de utilizações da A. satureioides em patentes voltadas para serviços em saúde humana, porém, nem todos os usos descritos pela medicina popular, através de estudos etnofarmacológicos, são abrangidos, evidenciando que ainda existem muitas possibilidades de inovação e desenvolvimento voltados para esta planta medicinal (Galvan, 2018; Guariniello, 2018; Salgueiro, 2016).

A espécie E. grandiflorus, popularmente conhecida como "chapéu-de-couro", é utilizada como planta medicinal no tratamento de diversas enfermidades no Brasil. Apesar de todas as indicações tradicionais, a literatura de pesquisa científica apoia principalmente duas indicações para seu uso: como um anti-inflamatório natural e uma planta medicinal diurética/antihipertensiva. As evidências científicas para essas indicações vêm de experimentos realizados com modelos de cultura de células in vitro e in vivo usando ratos saudáveis e hipertensos. Em relação às características fitoquímicas a E. grandiflorus apresenta em suas folhas diterpenos (do tipo clerodano e cembrano), flavonoides (C-heterosídeos de flavonas como a isoorientina e a swertiajaponina), derivados do ácido o-hidroxicinâmico (ácidos chicórico e caftárico), esteróides, ácidos graxos, arilpropanoides simples (ácido cafeico, ferúlico e isoferúlico) e ácido trans-aconítico (Marques, 2017; Dias, 2013).

O material vegetal comumente utilizado é composto pelas partes aéreas, normalmente utilizadas em preparações medicinais. No entanto, alguns estudos também citam o uso de rizomas na medicina tradicional. Dados da literatura mostram que seus rizomas são utilizados como cataplasma para hérnias, enquanto as partes aéreas, ou apenas as folhas, são utilizadas principalmente como diurético e tônico, que é indicado para fins depurativos e utilizado para inúmeras condições como doenças hepáticas, problemas renais (incluindo cálculos renais) e inflamação da bexiga. De acordo com esses usos, um extrato de metanol feito dos rizomas foi considerado por seu uso potencial em terapias para o controle da dor e inflamação. Os resultados sugeriram que o extrato metanólico dos rizomas do "chapéu-de-couro" possuía propriedades analgésicas que agiam sobre o sistema nervoso central e periférico, com componentes ativos apresentando propriedades antinociceptivas e antiinflamatórias, que poderiam ser de alto valor como uma terapia alternativa para dor e inflamação. A infusão de folhas de "chapéu-de-couro" também é usada para tratar desconfortos relacionados a reumatismo e artrite. Como gargarejo ou enxaguatório bucal, infusões aquosas têm sido indicadas para problemas de inflamação da garganta, como amigdalite e faringite, estomatite e gengivite, os chás podem combater a inflamação da garganta e promover a cicatrização de feridas (Carvalho 2018; Marques, 2017).

Curiosamente, extratos da espécie, que se correlacionam com suas propriedades diuréticas, têm sido usados na fabricação de dois refrigerantes no Brasil. Desde 1947 o refrigerante "Mate Couro®" é fabricado com a E. grandiflorus e o 
refrigerante "Mineirinho®" desde 1974. Essas bebidas são produzidas e consumidas popularmente principalmente nos estados do Rio de Janeiro e Minas Gerais. A espécie possui grande potencial para gerar inovação em preparações de formulações tópicas ou orais e ser usada como uma alternativa complementar em diversas doenças crônicas, no entanto, apesar deste longo uso comercial de extratos de "chapéu-de-couro", o uso de matérias-primas na forma de chás caseiros como preparações fitoterápicas ainda estão em estágios preliminares de estudo sobre os efeitos de seu uso e efeitos toxicológicos de longo prazo (Lima, 2006; Brugiolo, 2010; Lorenzi \& Matos, 2002).

A espécie vegetal S. terebinthifolius é uma planta nativa da América do Sul, amplamente encontrada na costa brasileira em especial na vegetação litorânea do nordeste e popularmente conhecida como "pimenta rosa" ou "aroeira vermelha". Essa planta fornece um fruto, utilizado como condimento refinado na culinária mundial, devido ao seu sabor levemente apimentado e de boa aparência além de sua utilização como árvore de ornamentação (Oliveira ${ }^{a}$, 2020; Santos, 2020). É tradicionalmente empregada na medicina popular para o tratamento de infecções urinárias, infecções respiratórias, feridas e reumatismo. O extrato da casca do caule é amplamente utilizado como anti-inflamatório, enquanto as frutas são utilizadas para resfriados, infecções fúngicas e bacterianas (Oliveira ${ }^{\mathrm{b}}$, 2020; Affonso, 2012). A espécie apresenta importantes atividades biológicas, como ação anti-hipertensiva, vasodilatadora, antimicrobiana, antialérgica, antioxidante, anti-inflamatória e mais recentemente, contra cepas multirresistentes de origem hospitalar (Oliveira ${ }^{a}$, 2020). Dessa forma a S. terebinthifolius torna-se uma grande alternativa quando ao uso em biotecnologia, de modo a apresentar bons resultados em atividade antimicrobiana, especificamente no que se refere a seu fruto, em que demonstrou em um experimento com Staphilococcus aureus coagulase positiva, resultados bem promissores (Silva, 2010). Em complemento, seu extrato alcoólico combateu espécies como S. aureus, Bacilo cereus, Pseudomonas aeruginosa e Escherichia coli, além de inibição fúngica (Sá Junior, 2016). Há também evidências cientificas de que o extrato vegetal da espécie apresentou efeito contra a espécie Enteroccocus faecalis em teste de sensibilidade de cultura (Costa, 2010).

Embora a composição química das plantas dependa da origem, maturidade, genótipo, clima, condições de processamento e outros aspectos, compostos como taninos, alcaloides, flavonoides, antocianinas, terpenos e ácidos fenólicos foram previamente determinados nos frutos da S. terebinthifolius (Oliveirab ${ }^{\mathrm{b}}$, 2020). Os compostos fenólicos são os principais constituintes e exercem importantes atividades biológicas como a ação antioxidante e fotoprotetora, devido à sua capacidade de combater espécies reativas de oxigênio e nitrogênio e por absorver a radiação ultravioleta (UV) (Oliveiraa $\left.{ }^{a}, 2020\right)$. O óleo essencial da espécie é muito utilizado na terapia de infecções respiratórias, devido a sua composição rica em terpenos, como $\alpha$ pineno, $\delta$ - careno, limoneno e $\alpha$-felandreno. Um exemplo da sua utilização é em casos de bronquite, que é usado em infusões de suas folhas. A casca da S. terebinthifolius ainda tem ação antitérmica, atua contra hemoptises e doenças uterinas, em geral (Pereira, 2021). Em um estudo utilizando uma pomada contendo 5\% do óleo essencial da aroeira sobre feridas cutâneas, foi observado o aumento da concentração de mastócitos, que são responsáveis por armazenar mediadores químicos da inflamação como a heparina, histamina e serotonina. Dessa forma, a utilização da pomada promoveu a contração de feridas, potencializando o processo de recuperação tecidual e o aumento da concentração de mastócitos. A aplicação tópica do óleo apresentou efeitos anti-inflamatórios e angiogênicos, melhora na reposição de colágeno, sugerindo o uso desta planta para o desenvolvimento de um novo fitoterápico para tratar doenças inflamatórias, incluindo a cicatrização de feridas (Estevão, 2017).

Nos resultados da busca de patentes foram encontradas formulações com ação anti-inflamatória, antimicrobiana, cicatrizante e em formulações cosméticas. Porém, nem todos os usos descritos pela medicina popular e suas potencialidades já descritas na literatura cientifica, são abrangidos. A S. terebinthifolius possui importância comercial por se tratar de uma planta com propriedades medicinais, fitoquímicas e alimentícias e pelo uso de seus frutos na cozinha nacional e internacional. Com essa pesquisa foi possível observar que a espécie possui resultados animadores quando avaliado seus potenciais biotecnológicos, apresentando bons resultados para utilização terapêutica em diversos casos (Pereira, 2021; Mendonça, 2014). 


\section{Considerações Finais}

Com base nos dados obtidos pode-se concluir que ainda é reduzido o número de depósitos de patentes envolvendo as espécies vegetais estudadas no setor de serviços e/ou produtos voltados para a saúde humana, visto que todas as espécies são descritas na literatura científica, são de uso comum na medicina popular e fazem parte da Farmacopeia Brasileira. Além disso, nem todos os usos descritos pela medicina popular, através de estudos etnofarmacológicos, são abrangidos. Devido à versatilidade de atividades biológicas das espécies estudadas, entende-se que estes recursos naturais podem ter um amplo emprego na área biotecnológica e ser utilizado na produção de fitomedicamentos para tratamento de diversas patologias. Todas as espécies estudadas apresentam grande potencial para o desenvolvimento de produtos, vindo a servir tanto como fitomedicamentos e/ou complementos alimentares, como também, em cremes de uso tópico e outros produtos em saúde. Existe uma necessidade de estudos mais aprofundados e de se registrar o conhecimento valioso dos medicamentos de uso popular, bem como da pesquisa em medicina de fontes naturais. Apesar do enorme potencial biológico do Brasil, o investimento na pesquisa, inovação e produção de novos medicamentos a partir de espécies vegetais ainda são escassos.

\section{Referências}

Affonso, C. R. G., Fernandes, R. M., Oliveira, J. M. G., Martins, M. C. C. E., Lima, S. G., Sousa Júnior, G. R., et al. (2012). Efeitos do óleo essencial de frutos de Schinus terebinthifolius Raddi (Anacardiaceae) nas funções reprodutivas de ratos machos. Jornal da Sociedade Brasileira de Química, 23(1), 180-185.

Brasil. (2016). Política e Programa Nacional de Plantas Medicinais e Fitoterápicos - PNPMF.

Carvalho, E. S. (2018). Estudo do mecanismo vasorrelaxante do extrato etanólico e frações, das folhas de Echinodorus grandiflorus (Cham. \& Schltdl.) Micheli, em leitos mesentéricos isolados. Dissertação, UFGD.

Costa, E. M. M. B., Barbosa, A. S., Arruda, T. A., Oliveira, P. T., Dametto, F. R., Carvalho, R. A., \& Melo, M. D. (2010). Estudo in vitro da ação antimicrobiana de extratos de plantas contra Enterococcus faecalis. J. Bras. Patol. Med. Lab., 46(3), 175-180.

Dias, E. G. E., Valenzuela, V. C. T., Alves, M. R., Duarte, M. G. R., \& Garcia, E. F. (2013). Qualidade e autenticidade de folhas de chapéu-de-couro (Echinodorus grandiflorus) oriundas de fornecedores de São Paulo. Rev. bras. plantas med., 15(2), 250-256.

Estevão, L. R. M., Simões, R. S., Cassini-Vieira, P., Canesso, M. C. C., Barcelos, L. S., Rachid, M. A. et al. (2017). Schinus terebinthifolius Raddi (Aroeira) leaves oil attenuates inflammatory responses in cutaneous wound healing in mice. Acta Cir Bras., 32(9), 726-35.

França, E., \& Vasconcellos, A. G. (2018). Herbal Medicine Patents In Brazil: An Analysis Of Status Of Patent Applications In The Period Of 1995-2017. Cadernos de Ciência\&Tecnologia, 35(3), 329-359.

Galvan, N.S. (2018). Teores de elementos essenciais e não essenciais em Achyrocline satureioides. Dissertassão, UDESC.

Guariniello, J., Iannicelli, J., Peralta, P. A., \& Escandon, A. S. (2018). Propagação in vivo e in vitro da "macela": planta medicinal aromática nativa com potencial ornamental. Ornam. Hortic., 24(4), 361-370.

Gutiérrez, I. E. M., Góes-Neto, A. (2012). Exploitation of Bioactive: Partnerships and Patents. Revista Fitos, 07(01).

hidroalcoólicos e alcoólicos de espécies da família anacardiaceae. Rev. Ciênc. Méd. Biol, 15(1), 56-61.

Lorenzi, H., Matos, F. J. A. (2002). Plantas medicinais no Brasil: nativas e exóticas cultivadas. (2a ed.), Instituto Plantarum.

Marques, A. M., Provance, D. W., Kaplan, M. A. C., \& Figueiredo, M. R. (2017). Echinodorus grandiflorus: Ethnobotanical, phytochemical and pharmacological overview of a medicinal plant used in Brazil. FoodChemToxicol., 109(2), 1032-1047.

Mendonça, V. M., Silva-Mann, R., \& Rabbani, A. R. C. (2014). Prospecção tecnológica de óleo essencial de aroeira-da-praia (Schinus terebinthifolius RADDI). Revista GEINTEC Gestão, Inovação e Tecnologia, 4(1), 704-715.

Oliveira, A. C. D., \& Ropke, C. D. (2016). The ten years of the National Policy of Medicinal Plants and Herbal Medicines (PNPMF) and the main obstacles in the production chain of plant extracts and herbal medicines in Brazil. RevistaFitos, 10(2), 95-219.

Oliveira, M. B. a, Valentim, I. B., Rocha, T. S., Santos, J. C., Pires, K. S. N., Tanabe, E. L. L., et al. (2020). Schinus terebenthifolius Raddi extracts: from sunscreen activity toward protection of the placenta to Zika virus infection, new uses for a well-known medicinal plant. Industrial Crops and Products., 152, 112503 .

Oliveira, V. S. ', Augusta, I. M, Braz, M. V. C., Riger, C. J, Prudêncio, E. R., Sawaya, A. C. H. F., et al. (2020). Aroeira fruit (Schinus terebinthifolius Raddi) as a natural antioxidant: Chemical constituents, bioactive compounds and in vitro and in vivo antioxidant capacity. Food Chemistry., $135,126274$.

Pereira, D. P., Silva, A. I. B., Nunes, L. E., Sá-Filho, G. F., \& Ribeiro, L. H. F. (2021). Potencial biotecnológico da aroeira vermelha (schinus terebinthifolius raddi): uma revisão narrativa. Revista Saúde e Meio Ambiente - RESMA-UFMS-Três Lagoas, 13(1), 25-37. 
Research, Society and Development, v. 10, n. 16, e189101623017, 2021

(CC BY 4.0) | ISSN 2525-3409 | DOI: http://dx.doi.org/10.33448/rsd-v10i16.23017

Sá Junior, P. F., Muniz, E. B., Pereira, N. A., \& Oliveira, M. A. S. (2016). Atividade antimicrobiana in vitro dos extratos aquosos,

Salgueiro, A., Folmer, V., Rosa, H. S., Costa, M. T, Boligon, A. A., Paula, F. R. et al. (2016). In vitro and in silico antioxidant and toxicological activities of Achyroclinesatureioides. JournalofEthnopharmacology, 194, 6-14.

Santos, A. A. J. C., Barros, B. R. S., Aguiar, L. M. S., \& Patriota, L. L. S. (2020). Schinus terebinthifolia leaf lectin (SteLL) is an immunomodulatory agent by altering cytokine release by mice splenocytes. Biotech, 10, 144 .

Silva, A. B., Silva,T., Franco, E. S., Rabelo, S. A., Lima, E. R., Mota, R. A., Câmara, C. A. G., Pontes Filho, N. T., \& Lima Filho, J. V. (2010). Antibacterial activity, chemical composition, and cytotoxicity of leaf's essential oil from Brazilian pepper tree (Schinus terebinthifolius Raddi). Braz. J. Microbiol, 41(1) 